\title{
Management and outcome of children with supraventricular tachycardia presenting to the emergency room of a tertiary centre in Nigeria
}

\author{
*Wilson E Sadoh ${ }^{1}$, Ogho O Olubor ${ }^{1}$, Gold O Osueni ${ }^{1}$, Queennette Daniel ${ }^{2}$
}

Sri Lanka Journal of Child Health, 2018; 47: 228-232

\begin{abstract}
Background: Supraventricular tachycardia (SVT) is the commonest arrhythmias in children. Prompt and appropriate treatment with adenosine and other medicines can be lifesaving.
\end{abstract}

Objectives: To determine the prevalence, management and outcome of children with SVT in an emergency room in a tertiary centre in Nigeria.

Method: This prospective, cross sectional and descriptive study was conducted between June 2013 and May 2017 among children from birth to 17 years of age who had SVT. Clinical information was obtained with the aid of a proforma. Electrocardiogram and echocardiogram were performed. The subjects were managed with vagal manoeuvre and administration of available medicines including adenosine, beta blockers and digoxin. Their responses to the treatment offered and outcomes were noted. Data was entered into and analysed with IBM-SPSS version 20.0.

Results: Twenty nine (0.4\%) of 7693 children seen during the study period had SVT. The median age was 4 months and $12(41.4 \%)$ were males. Seven $(24.1 \%)$ were unconscious and $14(48.3 \%)$ were either in heart failure or shock at presentation. Only four (13.8\%) had adenosine while 17 (58.6\%) received both beta blockers and digoxin of whom $50 \%$ responded. Eleven (37.9\%) children died.

Conclusions: In this study the prevalence of SVT was $0.4 \%$. Whilst $08(27.6 \%)$ children with SVT were treated only with vagal manoeuvres, 04 $(13.8 \%)$ were treated with adenosine, 09 (31.0\%) with metoprolol and $08(27.6 \%)$ with digoxin. Mortality was 38\%.

DOI: http://dx.doi.org/10.4038/sljch.v47i3.8544

\footnotetext{
${ }^{1}$ University of Benin Teaching Hospital, Nigeria, ${ }^{2}$ Zankli Medical Centre, Nigeria

*Correspondence: ehidiamen.sadoh@uniben.edu (Received on 07 September 2017: Accepted after revision on 27 October 2017)

The authors declare that there are no conflicts of interest

Personal funding was used for the project.

Open Access Article published under the Creative

Commons Attribution CC-BY (CC) (P) License
}

(Keywords: supraventricular tachycardia, adenosine, vagal manoeuvre)

\section{Introduction}

Supraventricular tachycardia (SVT) is the sudden onset of a rapid regular heartbeat that exceeds 220 beats per minute (bpm) in infants and $200 \mathrm{bpm}$ in older children and adolescents ${ }^{1}$. The SVT impulse arises from above the bundle of His and it is either due to a rapidly firing ectopic focus or a re-entry mechanism ${ }^{1}$. The re-entry mechanism involves an alternate or accessory pathway, which can either be atrio-ventricular or atrio-ventricular nodal re-entry tachycardia ${ }^{1}$. The SVTs that depend on the atrioventricular node (AVN) are the commonest form of $\mathrm{SVT}^{2}$. SVT is a common tachyarrhythmia in children with an incidence of 1:250 to $1: 1000$ individuals ${ }^{3,4}$.

A common cause of SVT in children in the emergency room is viral myocarditis and can be the first pointer to that diagnosis in affected children ${ }^{5}$. Other causes include post cardiac surgery in the intensive care units, complex congenital heart diseases like Ebstein anomaly and univentricular heart ${ }^{1}$. SVT can manifest with a stable cardiovascular state with normal blood pressure or in unstable state as in shock or heart failure ${ }^{4}$.

Some workers have classified the treatment of SVT into three different categories. Firstly, the initial treatment of SVT which is to abort the tachycardia with vagal manoeuvre or use of adenosine. Secondly, acute treatment of cases refractory to abortive measures with medications that reduce the heart rate or make the tachyarrhythmia more susceptible to be reverted to sinus rhythm. Thirdly, prevention of recurrence of SVT which requires maintenance treatment with antiarrhythmic medicines such as digoxin or amiodarone ${ }^{6,7}$.

Previous documentation of SVT in Nigerian children are case reports of single cases ${ }^{8,9}$. To the best of the authors' knowledge, studies on the incidence/ prevalence of SVT and the outcome of treatment of this condition have not been previously reported.

\section{Objectives}

To determine the prevalence, management and outcome of children with SVT in an emergency room in a tertiary centre in Nigeria 


\begin{abstract}
Method
The subjects were consecutive children aged from birth to 17 years who presented to the children's emergency room of a tertiary institution in Nigeria with SVT. The diagnosis of SVT was made by the attending physician based on a heart rate $>200 \mathrm{bpm}$ in infants and children and $>180 \mathrm{bpm}$ in adolescents with narrow QRS complexes on the ECG monitor. This was a prospective study carried out between June 2013 and May 2017. With the aid of a proforma, information on biodata and the socioeconomic class using the method described by Olusanya et $a l^{10}$ was collected. The other information obtained with the proforma were the presence of cyanosis, shock/ heart failure and unconsciousness at presentation. The heart rate as recorded using a stethoscope, the underlying diagnoses, especially if the child had congenital heart disease and outcome were documented.
\end{abstract}

The intervention for the SVT and the response to the intervention were noted. As a first line of action, vagal manoeuvres using icepacks on the face for 15 seconds were tried, if the patient was not in shock and the blood pressure was normal. If vagal manoeuvre was unsuccessful, adenosine, if available, was given to abort the tachycardia. When unavailable, intravenous metoprolol (an analogue of propranolol) was administered. Adenosine was given at a dose of $100 \mathrm{mcg} / \mathrm{kg}$ rapidly through a vein close to the heart such as a scalp vein or brachial vein and flushed with $5 \mathrm{ml}$ of injection water. If unresponsive, subsequent doses were increased by $50 \mathrm{mcg} / \mathrm{kg}$ up to a total dose of $300 \mathrm{mcg} / \mathrm{kg}$ and given two minutes apart according to the recommendation of the advanced paediatric life support ${ }^{11}$. Intravenous metoprolol was administered in a dose of $1 \mathrm{mg} / \mathrm{kg}$ in an infusion and repeated if necessary until a resolution of the SVT. Digoxin was given in a total digitalizing dose of $30 \mathrm{mcg} / \mathrm{kg}$. Half of the total daily dose (TDD) was given as start dose followed by quarter of the TDD 8 hours later and then a maintenance dose of $1 / 8$ TDD every 12 hours after a normal potassium level was confirmed. The beta blocker and digoxin were given in some cases on follow up until the SVT reverted to sinus rhythm. Diagnosis of shock was made clinically if the pulses were fast and of small volume and the blood pressure was low. Diagnosis of heart failure was made based on criteria described by Omokhodion et al. ${ }^{12}$.

The patients were placed on a multi-parameter monitor with ECG monitor. For detailed analysis, ECG was performed using a portable Schiller AT1 in the standard fashion. The tracings were read according to standard guidelines ${ }^{13}$. Transthoracic echocardiography was performed after the acute condition, with an Aloka Prosound SSD-4000SV (Aloka, Meerbusch, Germany) machine. Two dimensional (2D), $\mathrm{M}$ mode and Doppler imaging were employed. The report was analysed according to the recommendations of the American Society of echocardiography ${ }^{14}$.

Ethical approval for the study was obtained from the ethics and research committee of the University of Benin Teaching Hospital, Benin City, Nigeria.

\section{Statistical analysis}

Data from the proforma were coded and entered into an SPSS spread sheet and analysed. Simple proportions were represented in percentages. The means of continuous variables were compared with the student t-test while the data that were not normally distributed such as the age, the median ages of different variables were compared with the median test. Association between proportions was tested with the Chi-squared test or Fisher exact test as appropriate. Statistical level of significance was set at $<0.05$ at $95^{\text {th }}$ confidence interval.

\section{Results}

Over the study period, 7693 children were seen in the children's emergency room of which 29 children presented with SVTs, representing a prevalence of $0.38 \%$ or $1: 265$ children. The 29 children consisted of $12(41.4 \%)$ males and $17(58.6 \%)$ females. The median age (range) was 4 months (1 month -6 years). Fourteen $(48.3 \%)$ were from low socioeconomic strata while $10(34.5 \%)$ and $5(17.2 \%)$ were from high and middle classes respectively.

\section{Clinical findings}

Nine $(31.0 \%)$ were cyanosed clinically, while 07 $(24.1 \%)$ were unconscious with an average Blantyre coma score of $2 / 5$. Fourteen $(48.3 \%)$ were either in heart failure or shock. The cause was suspected to be myocarditis from bronchopneumonia in 19 (65.5\%) and diarrhoea in three $(10.3 \%)$. One case each of neuroblastoma and intussusception were the underlying conditions in two cases which were suspected to have caused the SVT. A case of possible caffeine (in coca cola) induced SVT. The remaining four had no identifiable trigger for the SVT.

\section{Electrocardiographic and echocardiographic findings}

Of the 29 subjects $21(72.4 \%)$ had their ECGs recorded and only five of the $21(23.8 \%)$ were recorded before intervention was commenced. Three $(14.3 \%)$ of the 21 patients had right bundle branch block and 1/21 (3.4\%) had left anterior hemi-block. Of the five who had pre-intervention ECG, all had narrow QRS complexes and no $\mathrm{p}$ wave preceding each QRS complex. (Figure 1). 


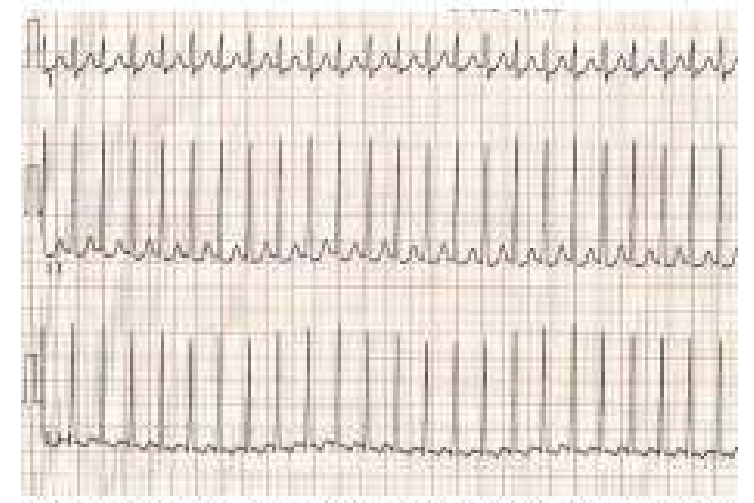

Figure I SVT in a 4 year old giri showing narrow QRS complexes

Echocardiography was done in 14 subjects, of whom $04(28.6 \%)$ had congenital heart disease. The other findings are shown in table 1.

\section{Treatment of the SVT}

Eight $(27.6 \%)$ children had vagal manoeuvres only. In one 4 year old girl cardioversion was induced by vomiting. The other 22 children were given antiarrhythmic medicines. Four $(13.8 \%)$ had adenosine. Of the three $(75 \%)$ who responded to adenosine administration, one responded to the first dose while the other two responded to the second dose. Seventeen $(58.6 \%)$ had beta blockers or digoxin. Of these, 15 had their heart rates reduced to normal within 7 days, while in the other two, normal heart rates were achieved in the second week. The interventions / medicines given and the responses are shown in table 2 .

Table I

Echocardiographic findings in 14 subjects

\begin{tabular}{|l|c|}
\hline \multicolumn{1}{|c|}{ Findings } & Number (\%) \\
\hline Atrial septal defect (ASD) & $02(14.3)$ \\
\hline Myocarditis & $02(14.3)$ \\
\hline Patent ductus arteriosus/ASD & $01(07.1)$ \\
\hline Ventricular septal defect & $01(07.1)$ \\
\hline Pericardial effusion & $01(07.1)$ \\
\hline Normal echocardiogram & $07(50.0)$ \\
\hline \multicolumn{1}{|c|}{ Total } & $\mathbf{1 4}(\mathbf{1 0 0 . 0})$ \\
\hline
\end{tabular}

Table 2: SVT interventions and the responses

\begin{tabular}{|c|c|c|c|}
\hline \multirow{2}{*}{ Intervention } & \multicolumn{2}{|c|}{ Response } & \multirow{2}{*}{$\begin{array}{c}\text { Total } \\
\text { Number (\%) }\end{array}$} \\
\cline { 2 - 4 } & $\begin{array}{c}\text { Yes } \\
\text { Number (\%) }\end{array}$ & $\begin{array}{c}\text { No } \\
\text { Number (\%) }\end{array}$ & \\
\hline Vagal manoeuvre only & $04(50.0)$ & $04(50.0)$ & $08(100.0)$ \\
\hline Adenosine & $03(75.0)$ & $01(25.0)$ & $04(100.0)$ \\
\hline Metoprolol & $07(77.8)$ & $02(22.2)$ & $09(100.0)$ \\
\hline Digoxin & $06(75.0)$ & $02(25.0)$ & $08(100.0)$ \\
\hline \multicolumn{1}{|c|}{ Total } & $20(69.0)$ & $09(31.0)$ & $29(100.0)$ \\
\hline
\end{tabular}

\section{Outcome}

Of the 29 children 18 (62.1\%) survived and were discharged home while $11(37.9 \%)$ died. Two of the 11 that died had cardioversion of their arrhythmia but died from their underlying conditions which were one case each of diarrhoea and bronchopneumonia. The 11 mortalities comprised four $(36.4 \%)$ males and seven $(63.6 \%)$ females. The median ages of those that died $5(1-48)$ years, was not significantly different from the survivors 4 (18 ) months, $p=0.70$. There were no deaths recorded among those with congenital heart disease.

\section{Discussion}

In this study, a large proportion (8/29) of the children had vagal manoeuvre alone to abort the SVT because of non-availability of adenosine or other medicines/ defibrillator to abort the SVT. This is at variance with studies from developed countries where administration of adenosine/ cardioversion are provided as appropriate without delay ${ }^{3,15}$. It is also noteworthy that only 4 children had adenosine to abort their SVT in this study. Adenosine being the medicine of choice to abort SVT, should be an important component of the emergency tray. In this setting, adenosine was not regularly available because of the high cost. Another factor that militated against its regular availability was the infrequent presentation of SVT to the emergency room leading to expiration of the infrequently used adenosine. Therefore, the regular purchases of this expensive medicine with its high probability of expiring in the emergency tray amidst the multiple competing interests for available scarce resources in a resource constrained country such as Nigeria was difficult.

Half of the children who had only vagal manoeuvre, which was the application of ice pack to the face reverted back to sinus rhythm. A 50\% success rate was obtained in this study. This value is within the $33-62 \%$ success recorded from previous works ${ }^{16}$. One of the children, a 4 year old, had their SVT reverted to sinus rhythm after vomiting. Vomiting is one of the ways of inducing Valsalva manoeuvre which may have stopped the SVT. The 75\% response rate for adenosine in this study, is consistent with previous report where response of $72-77 \%$ were obtained ${ }^{3,15}$. 
The poorly available adenosine resulted in most of the children receiving other medicines meant to be prophylactics for preventing recurrence of SVT. The use of propranolol (a beta blocker) and digoxin as prophylactics in the treatment of SVT have been previously documented ${ }^{17}$. Although there was no immediate cardioversion of the arrhythmia, the rates were brought down sufficiently for better perfusion and ultimate abortion of the SVT over the course of several days to a week in the majority of cases. Even though the use of these medicines is not ideal to abort SVT, it however provided an important intervention in a situation that could have led to death in some of these children.

Over $75 \%$ of the children had underlying bronchopneumonia or diarrhoea both of which were suspected to be caused by viruses. Viral myocarditis is a well-documented trigger for SVT in children ${ }^{5}$. Although viral studies were not done in the present study, viral aetiology was strongly suspected in these cases of bronchopneumonia and diarrhoea.

The mortality recorded in this study is high when compared to the $2 \%$ recorded in a multicentre study in the United States ${ }^{7}$. A number of reasons could account for this finding. About half of the children presented in shock or heart failure indicating significant cardiovascular instability at presentation. These cases ideally would require electrical cardioversion as a first line intervention. Defibrillator was however unavailable and this may have contributed to the high mortality recorded in this study. Another possible reason is the late presentation of patients to the hospital, although late presentation was not evaluated in this study, it however has been documented in previous studies amongst patients from the study locale ${ }^{18}$. The underlying condition may also have contributed to the mortality as two cases in whom their SVT were aborted only to later succumb to the illnesses, were noted. High mortality amongst children with SVT and comorbidities have similarly been documented $^{19}$.

There was no mortality in children with congenital heart disease in this study. This is at variance with a previous report that had shown that mortality was higher in children with congenital heart disease compared with those without the condition ${ }^{7}$. This may have been due to the small sample size in this study.

In this study, the incidence of SVT of 1:265 is consistent with the documented range of 1:250 to $1: 1000$ children $^{2,3}$. It is pertinent to note however that the denominator of the value obtained in the present study is the population of children presenting in the emergency room rather than the general population. It is possible that the value will be much smaller if the denominator is the general population. The difficulty with regular supply of adenosine can be ameliorated by networking between paediatric cardiologists and pharmacists across the country to make available adenosine and other lifesaving medicines to centres that require them before they expire.

\section{Conclusions}

- In this study the prevalence of SVT was $0.4 \%$.

- Whilst $27.6 \%$ children with SVT were treated only with vagal manoeuvres, $13.8 \%$ were treated with adenosine, $31 \%$ with metoprolol and $27.6 \%$ with digoxin.

- $\quad$ There were 11 (38\%) deaths.

\section{References}

1 Park MK. Myocarditis. In. Pediatric cardiology for practitioners. $5^{\text {th }}$ ed. Mosby Elsevier Philadelphia PA. $2008 ; 360-4$

2 Lundberg A. Paroxysmal tachycardia in infancy: a clinical and experimental study. Acta Paediatrica 1963; 52: 192-5.

https://doi.org/10.1111/j.16512227.19 63.tb03766.x

3 Losek JD, Endom EE, Dietrich A, Stewart G, Zempsky W, Smith K. Adenosine and supraventricular tachycardia in emergency department: multicentre study and review. Annals of Emergency Medicine 1999; 33: 185 -91 .

https://doi.org/10.1016/S01960644(99 )70392-6

4 Manole MD, Saladino RA. Emergency department management of paediatric patient with supraventricular tachycardia. Pediatric Emergency Care 2007; 23: 176 - 89.

https://doi.org/10.1097/PEC.0b013e3 18032904c

PMid: 17413437

5 Aypar E, Asian E, Sert A, Odabas D. Different spectrum of arrhythmia in myocarditis: QT interval prolongation followed by supraventricular tachycardia. Journal of Clinical and Analytical Medicine 2016; 7: 408-10. https://doi.org/10.4328/JCAM.1494

6 Wong KK, Potts JE, Etheridge SP, Sanatani S. Medications used to manage supraventricular tachycardia 
in the infant: a North American survey. Pediatric Cardiology 2006; 27: 199203.

https://doi.org/10.1007/s00246-005-

1126-x

PMid: 16391988

Chu PY, Hill KD, Clark RH, Smith B, Hornik CP. Treatment of supraventricular tachycardia in infants: analysis of a large multi-centre database. Early Human Development 2015; 91: 345-350.

https://doi.org/10.1016/j.earlhumdev. 2015.04.001

PMid: 25933212 PMCid: PMC4433846

Sadoh WE, Obaseki DE, Amuabunos EA, Eregie CO, Isah IA, Idemudia E et al. Cardiac rhabdomyoma in a neonate with supraventricular tachycardia. World Journal for Pediatric and Congenital Heart Surgery 2014; 5: $110-3$.

https://doi.org/10.1177/21501351135

01899

PMid: 24403367

Sadoh WE, Okonkwo IR. Supraventricular tachycardia in a neonate with Wolff-Parkinson-White syndrome. Nigerian Journal of Cardiology 2015; 12: 151 - 3. https://doi.org/10.4103/01897969.152 036

Olusanya O, Okpere E, Ezimokhai M. The importance of socioeconomic class in voluntary fertility control in a developing country West African Journal of Medicine 1985; 4: 205 - 12.

Berg MD, Berman JM, Conley L, de Caen AR, Donoghue A, Hamilton MLF. Recognition and management of tachycardia. In: Chameides L, Samson RA, Schexnayder SM, Hazinski MF, editors. Paediatric advanced life support provider manual. 2011, pp130 PMCid: PMC3251489

Omokhodion SI. Childhood heart failure. In: Omokhodion SI and Osinusi K. (Eds). Pediatric cardiology and respiratology. WACP update series (West African College of Physicians, Lagos, Nigeria) 1996. Pp $72-82$.
Park MK, Guntheroth WG. Basic measurements. In. Park MK, Guntheroth WG editors. How to read paediatric ECGs. St Louis, MO: Mosby Year Book, 1992; Pp 10 - 32

American Society of Echocardiography. Recommendations for continuous quality improvement in echocardiography. Journal of the American Society of Echocardiography 1995; 8: S1 - 28.

PMid: 8588940

Till J, Shinebourne EA, Rigby ML et al. Efficacy and safety of adenosine in the treatment of supraventricular tachycardia in infants and children. British Heart Journal 1989; 62: 204 11.

https://doi.org/10.1136/hrt.62.3.204

Muller G, Deal BJ, Benson DW Jr. 'Vagal manoeuvres' and adenosine for termination of atrio-ventricular reentrant tachycardia. American Journal of Cardiology 1994; 74: 500 - 3. https://doi.org/10.1016/00029149(94) 90914-8

Hornik CP, Chu PY, Li JS, Clark RH, Smith PB, Hill KD. Comparative effectiveness of digoxin and propranolol for supraventricular tachycardia in infants. Pediatric Critical Care Medicine 2014; 15: 839 -45 .

https://doi.org/10.1097/PCC.0000000 000000229

PMid: 25072477 PMCid: PMC4221410

Onabolu OO. Pattern of paediatric ophthalmic admissions in the Ogun State University Teaching Hospital, Sagamu. Nigerian Journal of Pediatrics 2002; 29:47-52. https://doi.org/10.4314/njp.v29i2.120 32

Salerno JC, Garrison MM, Larison C, Seslar SP. Case fatality in children with supraventricular tachycardia in the United States. Pacing and Clinical Electrophysiology 2011; 34: 832 - 6. https://doi.org/10.1111/j.15408159.20 11.03073.x PMid: 21418251 